\title{
Crisis teatral en Madrid durante el Trienio Liberal
}

\author{
Crisis in the Madrid Theater Scene \\ during the Triennal Liberal Government
}

\author{
Rosalía Fernández Cabezón \\ Universidad de Valladolid
}

\section{RESUMEN}

El Ayuntamiento madrileño, en la primavera y verano de 1820, incumple sistemáticamente el Reglamento de Teatros aprobado por la Regencia en 1812, por lo cual los directores de las dos compañías cómicas, Bernardo Gil y Antonio González, efectuarán infructuosas gestiones a fin de que el Consistorio aplique las leyes constitucionales, lo que provoca una grave crisis teatral agudizada porque los espectadores prefieren acudir a otros recintos de carácter más político. Ante la falta de respuesta de las autoridades locales los directores suspenden las funciones durante unos días en el mes de agosto y publican un Manifiesto en el que justifican su postura. Para la temporada siguiente los regidores municipales elaboran una normativa que contraviene el ordenamiento teatral de la Regencia, de ahí que Bernardo Gil redacte un Proyecto de Refor $m a$, fechado en abril de 1821, en el que además de una propuesta dramática integral defenderá con sólidos argumentos los derechos que tienen los cómicos como ciudadanos que ganan su sustento desempeñando una actividad honrada.

Palabras Clave: Crisis teatral, Trienio Liberal, Actores versus Ayuntamiento madrileño.

\begin{abstract}
In the spring and summer of 1820 , the Madrid City Hall systematically failed to comply with the Reglamento de Teatros dictated by the Regency in 1812. The directors of the two troupes, Bernardo Gil and Antonio González, attempted in vain to have the constitutional laws enforced. This provoked a serious crisis made worse by the fact that the spectators also showed a preference for other more political venues. The lack of response on the part of the local authorities led the directors to cancel performances for several days in August and to publish a Manifiesto explaining their decision. When, for the following season, the aldermen drew up a new set of regulations which once again contravened the Regency's Regulations, Bernardo Gil proposed his own Proyecto de Reforma, dated en April of 1821. Apart from a comprehensive proposal for theatrer reform he advances sound arguments defending the actors' rights as citizens who make an honest living in an honorable profession.
\end{abstract}

Key words: Theater Crisis, Triennial Liberal Government, Actores vs. Madrid City Hall. 
En la mañana del $1^{\circ}$ de enero de 1820 el teniente coronel Rafael del Riego proclama en Las Cabezas de San Juan (Sevilla) la Constitución de Cádiz. Este gesto, aunque no estaba previsto por los organizadores del alzamiento (Alcalá Galiano, 1955: II, 17-19), se convirtió en simbólico y trascendió a toda la nación. El éxito inicial hace de Riego el centro de la libertad restaurada (Gil Novales, 1980: 3) y extiende el movimiento revolucionario a otras ciudades, hasta que finalmente Fernando VII el 9 de marzo promete marchar «por la senda constitucional» jurando el Código de 1812 (Artola, 1999: 404-405).

Esta decisión fernandina tendrá repercusión inmediata en los teatros madrileños, cuyos directores solicitan al Ayuntamiento- de quien dependen los coliseos de la Cruz y del Príncipe- que entre en vigor el Reglamento de Teatros aprobado por la Regencia en Cádiz el 11 de diciembre de 1812. Este documento simplifica (sólo contiene cinco artículos) ${ }^{1}$ y clarifica legislativamente el ordenamiento en materia teatral que deberá regir en todas las localidades del reino, frente a los complejos y restrictivos reglamentos de finales del sexenio absolutista, impuestos por el corregidor José Manuel de Arjona en beneficio de las arcas municipales y en detrimento de los intereses económicos y morales de los cómicos madrileños (Cotarelo y Mori, 1902: I, 431$433)^{2}$.

El primero en tomar la pluma es el autor (director) del coliseo de la Cruz, Bernardo Gil (1772-1832) ${ }^{3}$, conocido por su militancia liberal, no en vano fue encarcelado la noche del 10 al 11 de mayo de 1814 junto a otros actores de la talla de Isidoro Máiquez (Cotarelo y Mori, 1902: I, 369) y habilitado políticamente desde el mismo 9 de marzo pasado ${ }^{4}$. Como representante de su compañía, antes de empezar la temporada escénica, se dirige a las autoridades a fin de que entre en funcionamiento el mencionado Reglamento de la Regencia. Sin embargo, unos días después recibe «con gran sorpresa» la resolución de la corporación, quien ordena que «sigan como hasta aquí» (p. 6), es decir, que apliquen el Reglamento de 1819 preescrito por Arjona, en el cual se ve «con toda claridad la absoluta privación de la libertad individual de los actores» (p. 4), al amenazar con enviar a provincias a los cómicos que no se avengan a firmar sus condiciones y, por lo tanto, es contrario al decreto de la Regencia de diciembre de 1812. El 30 de marzo, ante la inminente apertura

${ }^{1}$ Este Reglamento de Teatros se recoge íntegro en el Manifiesto que dan los autores en representación de los individuos de los teatros de la Cruz y Príncipe al respetable público de esta heroica villa. Madrid. Imprenta de Repullés: 1820, pp. 4-5. Este Manifiesto se fecha en Madrid a 31 de agosto de 1820 y lo firman Bernardo Gil y Antonio González. Es la edición a la que remiten las citas insertadas entre paréntesis en el texto.

${ }^{2}$ Estos reglamentos del corregidor Arjona los publica Cotarelo y Mori (1904, 718-722).

${ }^{3}$ La revista Cartas Españolas, V, Cuaderno 55, 7 de junio de 1832 (pp. 269-270), dedica a Bernardo Gil una elogiosa reseña con motivo de su reciente fallecimiento en la Corte el día 15 de mayo de ese año.

${ }^{4}$ Archivo de la Villa (Madrid), Corregimiento (1-63-11). 
de los teatros el domingo de Pascua, Gil se dirige de nuevo en una Exposición al Sr. Alcalde Constitucional para recordarle que no se está cumpliendo el Reglamento aprobado en Cádiz, a pesar de que «el Jefe Político de la Provincia lo remitió con el expediente al Excmo. Sr. Ayuntamiento» (p. 7). Esta Exposición no quiere ser certificada por la corporación municipal madrileña, por lo cual, el autor presenta, el mismo día 30 de marzo, un Recurso como apoderado de la compañía de la Cruz, en el que con valentía pero también con suma prudencia acusa al Consistorio de impedir lo dispuesto en el artículo $1^{\circ}$ del Reglamento de 1812 y, en consecuencia, se niega a aceptar las imposiciones municipales al escribir:

Como ni en la Constitución ni en el Reglamento se dé atribución a los Ayuntamientos para otra cosa (con respecto a los teatros) que para hacer los convenios que consideren oportunos, conciliando el interés de la empresa con el de los pueblos $^{5}$, y ningún convenio específico se haya señalado a la compañía, que es el empresario, no es posible adoptar la propuesta de que sigan como el año pasado. (p. 8).

En definitiva, la postura de los regidores del municipio hasta esa fecha sugiere que no quieren perder los seculares privilegios sobre los coliseos, dado que éstos generan cuantiosos ingresos a la hacienda local. En este sentido, coincidimos con Gil Novales quien considera que tanto el Ayuntamiento, encabezado por Pedro Sainz de Baranda, como el gobierno de la provincia, al mando de Miguel Gayoso de Mendoza, el señor de Rubianes, no sólo está formado por reaccionarios desde el inicio del Trienio Liberal, sino que además son, como los acontecimientos posteriores demostrarán, claramente contrarrevolucionarios (1975: I, 24, 622).

El domingo de Resurrección está próximo y el conflicto entre las autoridades y las compañías sigue sin resolverse, por ello, el director del Príncipe, Antonio González, se suma a las iniciativas de Gil y ambos «sin perjuicio alguno de los derechos que les competían» (p. 9) unen voluntades a la hora de redactar dos escritos. En primer término, un sucinto pliego con fecha 31 de marzo, dirigido a Su Majestad, en el que además de informarle de todas las gestiones precedentes, solicitan del monarca que sancione con su firma el Reglamento de Teatros de la Regencia y que ordene publicarlo y acatarlo, puesto que en 1813 no pudo ratificarlo al encontrarse prisionero en el sur de Francia.

Más explícito es el Memorandum enviado a la Suprema Junta provisional ${ }^{6}$

${ }^{5}$ Bernardo Gil subraya lo dispuesto en el artículo $1^{\circ}$ del Reglamento de Teatros de 1812, que reza así: Los Ayuntamientos harán por sí con los empresarios de las compañías cómicas los convenios que consideren oportunos, conciliando el interés de la empresa con el de los pueblos.

${ }^{6}$ Gil Novales $(1975$, I, 24, n. 40) cita a todos los miembros que formaban esta Junta y comenta que si alguno de ellos podía ser considerado liberal (Ballesteros), se hallaba neutralizado por los demás. 
el $1^{\circ}$ de abril, en el que detallan las diligencias efectuadas ante el Consistorio y el Jefe Político. Lo más significativo de este segundo documento es, sin duda, un Exordio en el que los autores manifiestan su ideología liberal, moderada en el caso de Gil, y más radical en el de Antonio González, uno de los pocos cómicos de clara filiación comunera a partir de 1821 (Gil Novales, 1975: I, 605-606). En estas líneas introductorias los autores defienden los pilares de la Constitución de 1812:

Firmada por el Rey la Constitución, y desapareciendo la desigualdad entre los ciudadanos españoles, desaparecieron igualmente los juzgados privativos y jueces comisionados, reuniendo todos los ciudadanos a una ley y a un fuero. Conforme al espíritu y letra del sagrado Código, la Regencia del reino que legítimamente gobernaba en la cautividad de nuestro Rey, estableció un reglamento para los teatros en que prescribió varios artículos, en los que señala los límites de los Ayuntamientos, las facultades de los mismos, las de los Jefes superiores y los jueces que en los casos contenciosos deben entender en las causas. Apenas podría dudarse cual es el deber de cada uno a vista del Reglamento, y en él se demuestra el respeto que debe tenerse por la propiedad tanto Real como industrial, quitando aquellas trabas que marcaban más la esclavitud que otra cosa. (p. 11).

Aunque el 2 de abril se inicia la temporada según el plan preconstitucional de Arjona de 1819, los dos escritos precedentes parecen, de momento, abrir una puerta a la esperanza en el ánimo de los preocupados cómicos, pues el 9 de ese mismo mes el Ministerio de la Gobernación, dirigido por Josef García de la Torre (Gil Novales, 1991: 276), expide una Real Orden en la cual el Rey sanciona el Reglamento de Teatros de 1812 y, lo que puede ser más eficaz, se lo comunicará al Jefe Político y al Ayuntamiento para su inmediata entrada en funcionamiento. A pesar de esta resolución, el Ayuntamiento madrileño, unilateralmente, incumplirá la Real Orden de Su Majestad, dado que no quiere prescindir de sus tradicionales privilegios sobre los coliseos, y como los directores de los mismos no están dispuestos a soportar las graves e injustas cargas a las que están sometidos, elevan otro recurso fechado el 26 de abril a la corporación local, institución anclada todavía en un régimen absolutista porque ni tan siquiera se digna contestar a los actores. Esta crisis teatral se ve agravada por la falta de espectadores, atraídos quizás por otros recintos de carácter más político, como son las Sociedades Patrióticas, así lo atestigua el periódico moderado La Colmena el jueves 18 de mayo de 1820:

Con el ínfimo semblante que miran los médicos y boticarios la salud pública, y los procuradores, agentes y escribanos la disminución de pleitos, ven los cómicos las sociedades patrióticas Constitucionales de los cafés de Lorencini, y S. Sebastián y sus ramificaciones. Si los teatros presentaran escenas de patriotismo; si las horas pudiesen variarse, y no fuera necesaria la bilocación para disfrutar de una y otra concurrencia; entonces no murmurarían los actores, y tendrían el consuelo de verse favorecidos de los que ahora se ocupan en cosas más importantes. Entretanto que dura esta crisis, pueden ejecutar sus talentos en estudiar, y ensayar las mejores composiciones dramáticas, y luego lucirán más y recogerán el fruto de sus tareas. (pp. 199-200). 
En efecto, si repasamos la dinámica prensa del Trienio se comprueba que durante la primavera de 1820 el público sólo acude con cierta asiduidad a presenciar piezas de enardecimiento patriótico, buena parte de las mismas representadas en el anterior periodo liberal, así la alegoría España libre (1808) de Agustín Juan Poveda, La Constitución vindicada (1813) de Francisco de Paula Martí o La palabra Constitución, esta última escenificada en el Príncipe desde el 22 al 28 de abril, adaptación de la ejecutada en 1813, asignada a Zavala y Zamora, y que se basa en el sainete ¿Qué es Constitución? (1812) del mencionado Poveda (Fernández Cabezón, 2007: 153-170). Junto a éstas se reponen, entre otras, Virginia, en versión de Antonio Saviñón sobre el texto de Alfieri, Lo que puede un empleo de Martínez de la Rosa y El príncipe perseguido, una comedia antigua muy aplaudida en la centuria ilustrada (Andioc \& Coulon, 1996: II, 823), demandada ahora por la oportunidad del argumento ${ }^{7}$.

Sin embargo, también observamos algunos estrenos significativos. El 29 de abril en la Cruz una obra dedicada a homenajear al artífice de la revolución intitulada La entrada del héroe Riego en Sevilla de Francisco de Paula Martí (Freire, 1997: I, 294). Este dramaturgo repite éxito el 8 de junio con El hipócrita pancista o los acontecimientos de Madrid los días 7 y 8 de marzo del año de 1820, comedia en tres actos, donde se evocan los disturbios que precedieron a la proclamación de la Constitución en la capital (Larraz, 1991: 117-120), representada posteriormente en los teatros de las principales capitales de nuestro país 8 .

A pesar de que las autoridades incumplen sistemáticamente la Real Orden de 9 de abril y la situación económica es insostenible, las compañías siguen representando. Sin embargo, el día 26 de mayo reciben un oficio del Regidor comisario de teatros José Serra (Gil Novales, 1991: 621), en el cual se solicita la relación detallada de las cargas que deben soportar los dos coliseos madrileños. A los pocos días y por separado, como manda el pliego municipal, los dos autores remiten de manera rigurosa e impecable las partidas de gastos, lo que revela una magnífica y generosa gestión de sus fondos (pp. 1518) y demuestra en el caso concreto de Bernardo Gil, que es quien lleva en todo momento la iniciativa, que posee una formación integral, no sólo en las materias propias de su condición de artista consagrado, ya que une a su faceta primigenia de tenor el haber ejercido también de primer galán y ahora, retirado por enfermedad, desempeña la función de director escénico y responsable del coliseo de la Cruz, tareas que bien pudo aprender y desarrollar en

\footnotetext{
${ }^{7}$ El título completo de esta comedia barroca a nombre de tres ingenios (Belmonte, Moreto y Martínez de Meneses) es el siguiente: El príncipe perseguido y tirano de Moscovia.

${ }^{8}$ En Valencia se escenificó el 19 de octubre de ese año según recoge Izquierdo (1989: 284). En Sevilla se localiza el 5 de diciembre de 1820 (Aguilar Piñal, 1968: 27). En Barcelona en enero y febrero de 1823 (Suero Roca, 1990: III, 253). El Diario Mercantil de Cádiz anuncia el estreno para el 4 de agosto de 1820 en el teatro Principal.
} 
sus viajes por Italia y Francia. El documento contiene además una nota muy interesante, en la que se hace ver a las insensibles autoridades del Trienio como en tiempos del Antiguo Régimen la corona se preocupaba por el bienestar de los teatros proponiendo planes de reforma alternativos, así recoge la idea de que los coliseos españoles nunca alcanzarán esplendor al tener que destinar una parte sustanciosa de sus rendimientos a las obras de beneficencia, idea expuesta por Jovellanos en la Memoria sobre espectáculos y diversiones públicas (Jovellanos, 1997: 213) y cita el más cercano Plan de la Villa de 1806, en el que intervino Manuel José Quintana debido a su cargo de censor (Dérozier, 1978: 171-172), publicado en marzo de $1807^{9}$, y es precisamente un epígrafe de este Reglamento (Título II, Capítulo XI, Art. $1^{\text {a }}$ ) el que se reedita a pie de página; en él se declara que la prosperidad de los teatros debe depender del bienestar de los actores y del trato decoroso que éstos tienen que recibir de las autoridades competentes (p. 17).

Los datos financieros pedidos por el Consistorio muestran que es inviable que con esos desorbitados gravámenes, en los que se incluyen tanto las aportaciones a las instituciones benéficas como los alquileres de los teatros, las jubilaciones, la seguridad, la administración, etc. ${ }^{10}$, puedan hacer frente a los gastos diarios, de ahí que el coliseo de la Cruz, el lunes 12 de junio, anuncie por la prensa su descanso estival:

La sociedad de actores del teatro de la Cruz suspende (por ahora) sus funciones teatrales, según costumbre, en la temporada de verano: los señores abonados que lo hicieron por quince días de representación, no habiéndose ejecutado más que diez, se servirán acudir a la contaduría de este teatro, hoy 12 del corriente, desde once a una de la mañana, a recoger el importe de los cinco restantes, y sino lo hiciese, se les descontarán cuando se principie a trabajar ${ }^{11}$.

El requerimiento municipal tenía como finalidad dilatar, en su propio beneficio, la solución del conflicto, puesto que además de no admitir las propuestas de los directores, éstos reciben una Nota, fechada el 28 de junio, que les hace perder definitivamente la esperanza de que sus justas reivindicaciones obtengan el fruto merecido, puesto que se les ordena cumplir El Reglamento aprobado el $1^{o}$ de marzo (p. 19), a saber, el redactado por el corregidor Arjona antes de que Fernando VII jurara la Constitución de 1812, contraviniendo con ello una Real Orden sancionada por el monarca el 9 de abril pasado.

Sin visos de mejora, la compañía de la Cruz anuncia su reapertura para el 9 de julio con la obra Las funciones del Congreso ${ }^{12}$. Ese día en el Prínci-

\footnotetext{
${ }^{9}$ Este reglamento teatral de 1807 en el que intervino Quintana ha sido publicado por Cotarelo y Mori (1904: 696-714).

${ }^{10}$ En esta detallada relación el coliseo de la Cruz debe abonar en concepto de cargas 306.682 reales anuales. El del Príncipe aportará una cifra más elevada: 347.031 reales al año.

${ }^{11}$ El Universal Observador Español, lunes 12 de junio de 1820, p. 116.

${ }^{12}$ El Universal Observador Español, domingo 9 de julio-martes 11 de julio de 1820.
} 
pe se repone una versión del Duque de Pentiebre, titulada Fenelón o Las religiosas de Cambray, original de Marie-Joseph Chénier (Cotarelo y Mori, 1902: I, 310, n. 1), y se estrena con éxito - a juzgar por las entradas vendidas y porque se mantiene en escena hasta el 14- una pieza nueva anónima, El triunfo de la Constitución ${ }^{13}$, rematando la función con el famoso Himno de Riego.

Con fecha 14 de julio, los dos apoderados de las sociedades cómicas redactan otra Exposición al Ayuntamiento en la que, en primer término, denuncian las vejaciones que padecen porque las autoridades locales se niegan explícitamente a aplicar las leyes vigentes en materia teatral y quieren continuar según los criterios del Reglamento absolutista de 1819, lo que supone un notable desacato desde el punto de vista jurídico y, sobre todo, una actitud inmisericorde hacia los actores, que ven severamente perjudicados sus intereses económicos y el de sus familias debido a la deuda acumulada en esos meses. Consecuentemente, amenazan al Ayuntamiento con la única medida de presión que les queda, el cierre de los teatros si no se produce un acuerdo aceptable y además inminente (pp. 19-22).

Entretanto, los actores del Príncipe también se tomarán, desde el $1^{\circ}$ de agosto, sus vacaciones estivales. Pero antes, durante los cuatro últimos días de julio, y a modo de despedida, representarán el drama nuevo en dos actos titulado Enrique III de Castilla $^{14}$, el mismo que la compañía del Príncipe elige para homenajear al general Riego cuando éste visite la capital el 3 de septiembre, función tristemente célebre porque desvela la primera intervención directa contra la libertad por parte de las autoridades, ahora ya abiertamente antirrevolucionarias al decretar el destierro del carismático héroe (Gil Novales, 1975: I, 124-126).

Como el Ayuntamiento sigue sin contestar al recurso del 14 de julio, Bernardo Gil y Antonio González, ante su total indefensión, escriben el 14 de agosto al Jefe Político de la Provincia recordándole la infame situación en la que se encuentran porque no se han respetado los derechos constitucionales de los cómicos. En su escrito, a la par que defienden el orden liberal establecido, acusan al Ayuntamiento, presidido ahora por Félix Ovalle (Gil Novales, 1991: 494), de llevarles a la ruina económica, ya que en tan sólo cuatro me-

${ }^{13}$ El Universal Observador Español, domingo 9 de julio-vienes 14 de julio de 1820. Esta pieza se repone en el Príncipe la tarde del $1^{\circ}$ de enero de 1821, en la función para conmemorar el aniversario del alzamiento de Riego (Diario de Madrid, lunes $1^{\circ}$ de enero de 1821 , p. 8).

${ }^{14}$ El Universal Observador Español, viernes 28-lunes 31 de julio de 1820. Este drama, heroico nuevo en dos actos, se había representado en el teatro Principal de Cádiz los días 30-31 de mayo y $1^{\circ}$ de junio de 1820 para festejar el santo del monarca, según informa El Diario Mercantil de Cádiz. En Barcelona esta obra subió a las tablas en varias ocasiones durante el Trienio Liberal con el elocuente título de El Despotismo humillado (Suero Roca, 1997: IV, 194). 
ses han contraído una deuda de 220.000 duros, lo que alcanza, en la moneda más acuñada de la época, la ingente suma de 4.400 .000 reales entre las dos compañías; sin embargo, y a pesar de la miseria que soportan, los actores han seguido desempeñando su actividad como personas de orden, animados por un indiscutible sentimiento patriótico. Como muestra espigaremos algunos fragmentos que denotan la dignidad de los denunciantes ante la desgracia:

en últimos de Marzo del corriente año hicieron presentes a S. M. que el reglamento de teatros aprobado en $1^{\circ}$ de dicho mes, por el que se forzaba a todos los actores a conformarse con las condiciones que en él se establecían, privándole de ejercer su profesión en toda España al que no prestase su firma atacaba la libertad individual y los demás derechos de los que humildemente elevaban queja a la Majestad [...] los actores de los teatros de Madrid, siempre amantes del orden, guiados siempre por el profundo respeto que han tenido a los Magistrados y al Público, han trabajado este año, luchando desde el principio con tantos obstáculos [...] ¡Cuánta sería sin embargo la satisfacción suya si pudiesen continuar dando muestras de su patriotismo en la prosecución de su trabajo! pero la deuda se aumenta cada día, y ya no hay tesorero que supla, ni recurso alguno, y es también contra conciencia y la justicia el que se arruinen a sí propios y a sus familias... (pp. 22-24).

Por consiguiente, anuncian el cierre de ambos teatros al terminar la función del domingo 20 de agosto. Como los actores del Príncipe están todavía de descanso, el 19 de agosto Bernardo Gil envía otro aviso al Jefe Político con el fin de informarle del cese de las actividades teatrales el día 21. En efecto, los días 21 al 24 de agosto de 1820 los dos coliseos públicos de Madrid permanecen cerrados y, para satisfacción de los espectadores, sus directores teatrales escriben este Manifiesto datado el 31 de agosto. Pretenden que a la vista de los acontecimientos y a tenor de las cifras de endeudamiento, el respetable e imparcial público de esta heroica villa, a quien va dirigido, pueda juzgar el «proceder de unos individuos que en todos tiempos han dado muestras de su amor al orden y de su lealtad y patriotismo.» (p. 25). Es razonable pensar que los directores de los coliseos, amparándose en la amnistía general concedida el 17 de agosto de 1820 (Dérozier, 1978: 696), se crean más protegidos por el Gobierno y que, aparte de suspender las funciones, escriban este respetuoso pero contundente Manifiesto.

Algunos periódicos contemporáneos pronto se hacen eco de la publicación; así El Constitucional: o sea, Crónica científica, literaria y política, en su número del 4 de septiembre, interpola una sugerente reseña que pudo deberse a la pluma de Josef Luis Munárriz ${ }^{15}$, conocido por su filiación liberal: sale de la prisión de Pamplona cuando Fernando VII jura la Constitución, es nombrado diputado a Cortes por esa provincia y colabora en este diario madrileño (Dérozier, 1978: 691-693). En ella defiende a los despreciados cómicos y eleva la voz contra el despótico gobierno, contra la tiranía del Ayuntamiento,

${ }^{15}$ El Constitucional: o sea, Crónica científica, literaria y política, lunes 4 de septiembre de 1820 , pp. 3-4. 
contra las desorbitadas cargas que pesan sobre los teatros y contra las humillaciones que sufren. Se opone a que las fundaciones piadosas se sostengan con el trabajo honrado de los actores y a que los representantes municipales acudan a presenciar los espectáculos sin pagar. Esta encendida crítica se cierra aconsejando que el gobierno estimule y proteja las artes, reflejo de la formación ilustrada de su redactor.

Sin embargo, no todos son parabienes. Hemos encontrado un folleto titulado Madrid de luto. Grandes novedades ${ }^{16}$, en el que su autor, escondido tras el seudónimo de Un Pobrezuelo, aprovecha la suspensión de las funciones dramáticas para acusar a los cómicos de holgazanería y libertinaje, puesto que no respetan ni leyes ni autoridades y, lo que es más reprensible, los tacha de maliciosos e ignorantes por burlarse del Ayuntamiento y del sufrido público. Asimismo, les afea el desmedido lujo con el que viven, no reparando en gastos suntuarios. Este escrito, respuesta al Manifiesto de 31 de agosto, desautoriza a los directores de las compañías por quejarse de unas onerosas cargas que ellos no pagan al revertir en los precios de las entradas. Sus lamentos son exagerados porque hay días que recaudan más de 6.000 reales y eso sin esforzarse, ya que siempre interpretan las mismas piezas y no se esmeran en recitarlas. El autor — que a juzgar por su detallada información financiera pudiera tener algún cargo en el Consistorio madrileño- recuerda, no sin nostalgia, a la célebre Rita Luna y elogia al recién fallecido Isidoro Máiquez, a la vez que arremete contra algunas actrices coetáneas como Antera Baus (la segunda mujer de Bernardo Gil), Manuela Carmona o Agustina Torres. Para él, estas primeras figuras están sobrevaloradas, ganan 40.000 reales al año, y son menos útiles a la sociedad que cualquier costurera, por lo tanto, si desean llenar los coliseos y triunfar, deben estudiar, representar nuevos papeles y acatar las normas municipales, de lo contrario sufrirán un merecido castigo.

Como réplica a esta mordaz denuncia sale a la luz otro panfleto Madrid de Gala. Contradiciendo á el papel de Luto ${ }^{17}$. El desconocido autor inicia su diatriba acusando al Pobrezuelo de ignorar «los sagrados derechos que nos da nuestra amada Constitución». Frente a la negatividad del escrito precedente éste destila optimismo. El replicante se siente feliz al igual que los habitantes de Madrid y de España entera porque se ha convocado el Congreso Nacional, encargado de dictar «leyes sabias y justas en beneficio de todos los Ciudadanos», porque tenemos un rey constitucional y las Sociedades Patrióticas han franqueado sus puertas a fin de consolidar la opinión pública e ilustrar al pueblo. Seguidamente, pasará a defender a los cómicos, cuyo comportamiento ha sido ejemplar al avisar reiteradamente al Ayuntamiento de incumplir las normas teatrales, y justifica el cierre de los coliseos porque es el único medio de manifestar su descontento. Para este liberal declarado es

\footnotetext{
${ }^{16}$ Madrid, Imprenta Nueva. 1820. Firmado por Un pobrezuelo.

${ }^{17}$ En Madrid, Imprenta de Arjona, 1820. Anónimo.
} 
el Consistorio madrileño el responsable de la situación al permitir que las compañías acumulen cuantiosas pérdidas y, lo que es más detestable, por contravenir a sabiendas «nuestro código sagrado». Asimismo, aplicando el orden legislativo de 1812 en su dimensión más altruista, aboga por la igualdad de todos los españoles, incluidos los comediantes, que también gozan de la condición de ciudadanos, a los que hay que respetar puesto que viven de una actividad digna y se esfuerzan por ofrecer al auditorio obras novedosas y bien ejecutadas. Por último, opina que si los habitantes de la capital no asisten al teatro como en épocas precedentes, no es por culpa de los actores, sino debido a la existencia de otros locales como las Sociedades Patrióticas donde «se reúnen todos a escuchar el eco de la verdad», a las que él acude por ser «el amante de la Constitución».

La opinión pública obliga a los regidores municipales a tomar una rápida decisión, así el 6 de septiembre se reúnen los comisionados y envían los acuerdos al Diario de Madrid, se trata de las Condiciones bajo las cuales el Ayuntamiento Constitucional de esta M. H. villa admitirá las propuestas que se hagan a la empresa de los teatros de la misma, para el año cómico próximo venidero de 1821 a $1822^{18}$. Esta normativa lo único que pretende es retrasar la solución hasta la temporada siguiente y, lo que es más peligroso desde el punto de vista jurídico, contraviene en casi todos los artículos el ordenamiento teatral de la Regencia: mantiene sobre las compañías las cargas de las instituciones benéficas, el Ayuntamiento sigue cobrando una sustanciosa cifra por el alquiler de los coliseos, además de ejercer un férreo control sobre los enseres y caudales que se utilicen, el empresario es el responsable de que su compañía desempeñe la función todos los días del año, salvo disposiciones contrarias y, por último, no sólo no condona la deuda que ha llevado a la miseria a los actores, sino que endurece las condiciones al obligar al futuro empresario a adelantar en concepto de fianza la suma de 200.000 reales. Los únicos puntos en los que el Consistorio cede, porque no perjudican sus intereses económicos ni políticos, y se acomodan al Reglamento de la Regencia de 1812 son: la seguridad de los coliseos depende del Ayuntamiento y la formación, gobierno y dirección de las compañías queda a cargo del empresario.

Pienso que estas Condiciones, contrarias a derecho y, por tanto, inaceptables para el bienestar de los cómicos, junto con otros enfrentamientos con el Ayuntamiento, desfavorables en su resolución para las compañías teatrales ${ }^{19}$, son el detonante del Proyecto de Reforma para los Teatros de la Corte, fechado el 4 de abril de $1821^{20}$, atribuido con bastante fundamento por

\footnotetext{
${ }^{18}$ Diario de Madrid, jueves 7 de septiembre de 1820, pp. 338-339.

19 Archivo de la Villa (Madrid), Corregimiento (1-87-25).

${ }^{20}$ Proyecto de Reforma para los Teatros de la Corte, Madrid, Por Ibarra, Impresor de Cámara de S. M., 1821. Madrid 4 de abril de 1821. Es la edición a la que remiten las citas interpoladas en el texto.
} 
Cotarelo y Mori al director del coliseo de la Cruz, Bernardo Gil (1902: I, 490). En este estudio creo poder confirmar su autoría, aunque no estampe su firma como ocurre en el Manifiesto de agosto, quizás por temor a las represalias políticas (las sufrió en 1814 y se repetirán a partir de 1823), ya que en noviembre de 1820 se produce el primer síntoma de inestabilidad del régimen, motivado por los incidentes de El Escorial, durante los cuales el Gobierno permite la reapertura de las Sociedades Patrióticas, suspendidas por la Ley de 21 de octubre de 1820 (Gil Novales, 1975: I, 94-101), y al iniciarse febrero de 1821 tiene lugar la segunda crisis ministerial, debido a los graves altercados provocados en la capital por los Guardias de Corps (Pérez Garzón, 1978: 219-223).

Al modo ilustrado, y a fin de anticipar su pensamiento sobre la mejor gestión de los coliseos madrileños, el autor de este Proyecto lo prologa con los siguientes versos:

Llegó el día que, al pueblo, será en vano darle paja, pues ya no come paja: sólo dándole grano, come grano.

Reverso de la máxima de Iriarte

Frente a Iriarte que aboga — como otros escritores del Antiguo Régimenpor un arte elitista destinado a una minoría privilegiada por estudios y condición en la fábula El asno y el amo (XXVIII), nuestro reformista, en consonancia con la Constitución de Cádiz, apuesta decididamente por un teatro que pueda ser disfrutado por todos los ciudadanos que lo deseen, sin distinción de rango. La primera página de su discurso, de la que entresacamos algunos fragmentos, resuelve cualquier equívoco sobre el espíritu liberal moderado, pero sin fisuras, del que hará gala el autor en todo el texto:

Hace años que llorábamos en silencio la progresiva degradación de nuestros Teatros; y nuestros lamentos no eran tanto más dolorosos, cuanto llevaban por delante el convencimiento de la imposibilidad de su mejora, en medio de un gobierno que nada se cuidaba de la civilización e inocentes diversiones de su pueblo. [...] Una ley terrible marcada con el sello de la esclavitud que daba a la capital la preferencia de elección de actores, y prohibía a éstos la justa libertad de pasar a representar a las Provincias cuando la capital los necesitaba, bajo pena de ser separados del ejercicio y privados del derecho que tuviesen a la jubilación; y un mal fraguado y digerido reglamento anual que tan sólo respiraba arbitrariedad e ignorancia, dado por el Corregidor, era toda la protección que el gobierno dispensaba a esta clase de espectáculos. [...] No era dudosa la elección: y el pueblo Español, levantando el grito de libertad e independencia, se tronchó de una vez las cadenas que tenían cautivas a las ciencias, hasta el punto de querer impedir que las luces tan difundidas del siglo diez y ocho alcanzasen en el diez y nueve con sus rayos a nosotros. (p. 3). 
A continuación, plantea su Proyecto de Reforma, en el que sigue hasta en la distribución de los epígrafes la Memoria sobre los espectáculos y diversiones públicas de Jovellanos, de la que copia varios fragmentos. Este trabajo del político asturiano está influido en líneas generales por el Discurso imparcial y verdadero sobre el estado actual del teatro español, atribuido a Juan Pablo Forner, publicado en La Espigadera en otoño de 1790, es decir, unos meses antes de que D. Gaspar redacte su polémica Memoria (Fernández Cabezón, 1998: 419-431). Jovellanos y Forner, educados en el Antiguo Régimen, tienen un concepto elitista del teatro y del resto de las manifestaciones artísticas, de ahí que se refieran a las capas más bajas de la población con el despreciativo vulgo, mientras que Bernardo Gil, un liberal convencido, les denomina con los términos pueblo, pueblo respetuoso o ciudadanos, es decir, aplica el Código de 1812, restaurado en 1820. En este mismo sentido, tanto Forner como Jovellanos proponen en sus planes de reforma un teatro destinado a los estamentos privilegiados y otro de inferior calidad que pueda servir como espectáculo de masas para las gentes, a las que tachan de ínfima condición, probablemente inspirados por los Principes de la littérature (1764) del francés Charles Batteux (Fernández Cabezón, 2001: 454-455). Ahora bien, el extremeño modifica su intransigencia y se hace más permisivo en algunos aspectos, puesto que al publicar en 1796 su comedia La escuela de la amistad o el filósofo enamorado antepone un jugoso prólogo titulado Apología del vulgo con relación a la poesía dramática (Cañas Murillo, 1997: 37-55), motivado, según todos los indicios, por las adversas críticas recibidas en su propio círculo de amistades: las de Pedro Estala.

La teoría dramática que proponen los dos escritores del siglo XVIII es de signo clasicista en todas sus aseveraciones, influidos por el Memorial que Santos Díez González redactó en 1789 a fin de reformar los teatros de la villa de Madrid ${ }^{21}$, y que será el plan impuesto en la fracasada Reforma de 1799 (Cotarelo y Mori, 1902: I, 76-121). Por el contrario, los cambios interpolados por Bernardo Gil al discurso de Jovellanos revelan un profundo y bien entendido conocimiento de la Constitución de 1812, aduciendo al modo de Cicerón en su famoso Pro Sexto Roscio que la profesión de actor nunca fue vergonzante ni vil. Defiende la igualdad de todos los ciudadanos siempre que se dediquen a un trabajo honrado y honroso como es el suyo, por ello, no tiembla al elogiar a todos sus compañeros artísticos. Todos y cada uno, según su talento y aptitudes, desempeñan papeles sublimes, y en este sentido vuelve a demostrar una educación exquisita porque no sólo alaba a su mujer Antera Baus (Cotarelo y Mori, 1902: I, 335-337), también a otros actores de la valía de Isidoro Máiquez (p. 11) o a los cantantes Lorenza Correa y Manuel García, conocidos por sus numerosos triunfos en los coliseos de media

${ }^{21}$ Este Memorial (1789) de Santos Díez González lo publica Dowling al editar La comedia nueva de Leandro Fernández de Moratín (1970: 239-259). 
Europa (p. 14). Es más, Bernardo Gil, siempre respetuoso con los espectadores que asisten a las funciones teatrales, piensa que el público -independientemente de su rango social y de la instrucción que haya recibido- es capaz de emocionarse durante una representación escénica. Al inicio de este apartado leemos: la música es «un arte encantador, que hace resaltar con más sensación las bellezas de la ejecución dramática por el deleite de la armonía.» (p. 13). En esta definición se percibe la huella de las teorías sensualistas formuladas por Antonio Eximeno en su libro Del origen y reglas de la música (1774). Unos párrafos después se decanta por un criterio integrador respecto al binomio clásico ars-natura (Checa Beltrán, 2004: 264-266) al afirmar:

Sin los auxilios del arte, contemplaremos con admiración a la naturaleza, en todo cuanto nos presente propicia, pero siempre con pena en su estado salvaje; mas si se le dirige con sólido conocimiento de cuanto es capaz de producir, la veremos elevarse a lo más sublime de la perfección, sin que por eso dejen de aparecer algunos de aquellos fenómenos extraordinarios, que admiran y encantan... (pp. 14-15).

Por otro lado, a Bernardo Gil, que además de director escénico es tenor y actor, lo que más le preocupa son los intereses morales y económicos de las dos compañías, afectadas ambas por la misma situación catastrófica, desesperado porque los políticos del Trienio, la mayor parte doceañistas, al llegar al poder en 1820 no sólo no cumplen con las prerrogativas consensuadas en Cádiz, sino que traicionan la causa liberal desde el otoño de 1820, solicitando los sueldos atrasados del sexenio, y el ministro de Hacienda (Canga Argüelles), de forma irresponsable, los aprobará de los presupuestos del Estado (Dérozier, 1978: 699-700), mientras el resto de los españoles se ven abocados a la indigencia, al igual que sucede con los cómicos, quienes, lejos de ver aplicar el Reglamento de Teatros de 1812, son humillados por las autoridades municipales y gubernamentales, al no poder hacer frente a los gastos diarios de las compañías, lo que ha provocado ese inmenso endeudamiento que los directores detallan en el Manifiesto de 1820.

Con un criterio similar, nuestro reformista aboga por unas obras dramáticas de calidad (el grano), que los ciudadanos saben apreciar porque todos los componentes de las compañías teatrales se esmeran en la elección de las piezas, en la declamación, en el canto, en el baile, en la puesta en escena. Por el contrario, en un régimen autoritario sólo se permiten traducciones insulsas, refundiciones de obras barrocas, comedias y tragedias repetidas hasta el aburrimiento y no se pueden estrenar textos de valía porque o existe la censura previa o no hay escritores con suficiente ingenio; en cambio, los dramaturgos de mérito que en el Trienio han podido dar cauce a su iniciativa son aplaudidos por el publico, que asiste con lealtad y entusiasmo a los espectáculos programados, como lo demuestran las piezas patrióticas y políticas de los dos periodos liberales (Fernández Cabezón, 2007: 153-170).

Uno de los puntos que Jovellanos aborda sin demasiado interés y que 
Bernardo Gil analiza con acierto es el de la música y el baile ${ }^{22}$. Desarrolla lo expuesto en el Plan de la Villa de 1806-180723 al proponer una escuela de enseñanza en la cual puedan aprender los jóvenes de ambos sexos que tengan talento en cada una de las disciplinas artísticas. Esta novedosa doctrina se lleva experimentando desde hace tiempo en la península itálica, como sucede en Nápoles donde se rigen por el siguiente método:

en cualquiera de estos conservatorios se cultivan indistintamente los tres ramos importantes de la composición, parte instrumental y vocal, y los profesores no hacen más que seguir las huellas de la disposición natural de sus alumnos, o condescienden a sus inclinaciones sin la menor violencia. De tantos colegios de niñas como tenemos sin más objeto que el de infundirles una buena educación propia de su sexo, podría montarse uno con el fin determinado de la escuela-música... (pp. 15-16).

Por consiguiente, considera contrario a los intereses de los cómicos y del público que el corregidor José Manuel Arjona desmembrara ambos aspectos en los Reglamentos de 1818 y 1819. Este deseo de Bernardo Gil no llega a buen puerto en el Trienio Liberal y menos a partir de 1823, cuando nuestro autor es suspendido por motivos ideológicos durante la década ominosa. Eso sí, sus ideas en torno al aprendizaje de jóvenes talentos darán fruto en los años treinta, cuando se inaugure el Real Conservatorio de Música de María Cristina en 1831 (Sopeña Ibáñez, 1967).

El Proyecto no se cierra sin redactar unas Reglas que deberán observarse para la reforma de los teatros de la corte (pp. 20-31), basadas con pequeñas modificaciones en el mencionado Plan de la Villa de 1806-7. Finalmente, proporciona a los lectores los datos contables del teatro de la Cruz pertenecientes al quinquenio 1814-1819 (pp. 33-35), cifras que coinciden con las aportadas en el Manifiesto de 1820 y, por tanto, la autoría de Bernardo Gil que Cotarelo sospecha puede ser confirmada.

En suma, con este Proyecto de Reforma de 1821, el liberal Bernardo Gil pretende superar la grave crisis teatral provocada por las autoridades madrileñas desde la primavera de 1820 y agudizada porque los espectadores prefieren acudir a otros recintos de carácter más político, de ahí que apueste por una Reforma dramática integral, aceptable en sus planteamientos tanto para el Ayuntamiento como para los cómicos y, sobre todo, y no menos importante, defenderá con sólidos argumentos los derechos que éstos tienen como ciudadanos que ganan su sustento y el de sus familias desempeñando una actividad honrada.

\footnotetext{
${ }^{22}$ Jovellanos en su Memoria tan sólo denuncia el escaso gusto de la música teatral y la indecencia de las danzas ejecutas en la escena española (Jovellanos, 1997: 210).

${ }^{23}$ En concreto lo recogido en el Capítulo VIII, Artículo 4a (Cotarelo y Mori, 1904: 702).
} 


\section{BIBLIOGRAFÍA CITADA}

Aguilar Piñal, Francisco (1968). Cartelera prerromántica sevillana (1800-1836). Madrid: CSIC.

Alcalá Galiano, Antonio (1955). Memorias de D. Antonio Alcalá Galiano publicadas por su hijo. Obras escogidas de D. Antonio Alcalá Galiano, prólogo y edición de Jorge Campos. Madrid: Atlas.

Andioc, René \& Coulon, Mireille (1996). Cartelera teatral madrileña del siglo XVIII (17081808). Toulouse: Université de Toulouse-Le Mirail.

Artola, Miguel (1999). La España de Fernando VII. Madrid: Espasa.

Cañas Murillo, Jesús (1997). «Juan Pablo Forner y su Apología del vulgo con relación a la poesía dramática», Castilla. Estudios de Literatura. 22, pp. 37-55.

Checa Beltrán, José (2004). Pensamiento literario del siglo español. Antología comentada. Madrid: CSIC.

Cotarelo y Mori, Emilio (1902). Isidoro Máiquez y el teatro de su tiempo. Madrid: José Perales Martínez.

Cotarelo y Mori, Emilio (1904). Bibliografía de las controversias sobre la licitud del teatro en España. Madrid: Establecimiento Tipográfico de la Revista de Archivos, Bibliotecas y Museos.

Dérozier, Albert (1978). Quintana y el nacimiento del Liberalismo en España. Madrid: Turner.

Fernández Cabezón, Rosalía (1998). «Una atribución a Forner: Discurso imparcial y verdadero sobre el estado actual del teatro español (1790)», en Jesús Cañas Murillo y Miguel Ángel Lama (eds.), Juan Pablo Forner y su época (1756-1797). Mérida: Editora Regional de Extremadura, pp. 419-431.

Fernández Cabezón, Rosalía (2001). «Forner, crítico teatral de La Espigadera», Revista de Estudios Extremeños. LVII, pp. 439-458.

Fernández Cabezón, Rosalía (2007). «Constitución, patria y libertad en el teatro breve del primer cuarto del siglo XIX», en Alberto Ramos Santana (coord.), Lecturas sobre 1812. Cádiz: Ayuntamiento de Cádiz/Universidad de Cádiz, pp. 153-170.

Fernández de Moratín, Leandro (1970). La comedia nueva. Comedia en dos actos estrenada en el teatro del Príncipe, Madrid, 7 de febrero de 1782, introducción, notas y documentos de John Dowling. Madrid: Castalia.

Freire, Ana María (1997). «El teatro político durante el reinado de Fernando VII», en Guillermo Carnero (coord.), Historia de la Literatura Española. Siglo XIX. Madrid: Espasa Calpe. I, pp. 293-300.

Gil Novales, Alberto (1975). Las Sociedades Patrióticas (1820-1823). Las libertades de expresión y de reunión en el origen de los partidos políticos. Madrid: Tecnos.

Gil Novales, Alberto (1980). El Trienio Liberal. Madrid: Siglo XXI.

Gil Novales, Alberto (1991). Diccionario biográfico del Trienio Liberal. Madrid: El Museo Universal.

Izquierdo, Lucio (1989). «El teatro en Valencia (1800-1832)», Boletín de la Real Academia Española. LXIX, pp. 257-305.

Larraz, Emmanuel (1991). «El teatro de propaganda política de Francisco de Paula Martí durante la guerra de la Independencia y el Trienio Liberal», en Ermanno Caldera (ed.), Teatro politico spagnolo del primo ottocento. Roma: Bulzoni, pp. 105-124.

Jovellanos, Gaspar Melchor de (1997). Memoria para el arreglo de la policía de los espectáculos y diversiones públicas y sobre su origen en España, edición de Guillermo Carnero. Madrid: Cátedra.

Pérez Garzón, Juan Sisinio (1978). Milicia Nacional y revolución burguesa. El prototipo madrileño (1808-1874). Madrid: CSIC. 
Sopeña Ibáñez, Federico (1967). Historia crítica del Conservatorio de Madrid. Madrid: Ministerio de Educación y Ciencia.

Suero Roca, M ${ }^{\mathrm{a}}$ Teresa (1990 y 1997). El teatre representat a Barcelona de 1800 a 1830. Barcelona: Institut del Teatre. Tomos III y IV.

Fecha de recepción: 6 de septiembre de 2010

Fecha de aceptación: 23 de marzo de 2011 